\title{
The relationship between counselling methods after health check-ups and lipid profile improvement: a retrospective cohort study in Korea
}

Na yeon Kim

Chung Ang University Hospital

Jung-Ha Kim ( $\nabla$ girlpower219@cau.ac.kr)

https://orcid.org/0000-0002-7630-9501

Soo Hyun Cho

Chung Ang University Hospital

Seon Ah Kim

Chung Ang University Hospital

Research article

Keywords: Lipid profile, Cholesterol, Counselling, Dyslipidaemias, Health check-ups, check-ups, Preventive Health Services

Posted Date: May 19th, 2020

DOI: https://doi.org/10.21203/rs.3.rs-28274/v1

License: (c) (i) This work is licensed under a Creative Commons Attribution 4.0 International License. Read Full License 


\section{Abstract \\ Background}

Despite growing numbers of private health check-ups, it is not known whether post-check-up counselling and education can improve chronic disease management. It has previously been shown that, in general, these factors are crucial to chronic disease management. Therefore, this study aimed to determine which counselling methods should be employed, following private check-ups, for optimal chronic disease management.

\section{Methods}

Participants were 7,039 adults over the age of 20 , who received at least three check-ups from September 2013 to August 2019. All participants received the same form of counselling, three or more times consecutively. Three forms of counselling were examined: mail, telephone, and face-to-face. Chi-square tests, one-way analyses of variance, and Scheffé post-hoc analyses were performed to determine the relationship between various demographic characteristics and counselling methods received. We performed covariance analyses after adjusting for age, sex and number of examinations to determine the correlations between the counselling methods and changes in health indicators. When necessary, Bonferroni pairwise comparisons were performed.

\section{Results}

The face-to-face counselling group was the oldest and had the poorest cardiometabolic parameters and glucose metabolic indices. However, face-to-face counselling was associated with the greatest improvement in levels of total cholesterol $(P<0.001)$ and low-density lipoprotein cholesterol $(P<0.001)$.

\section{Conclusion}

Face-to-face counselling with doctors seems to be more effective at improving lipid profiles than phone or mail counselling. Further research is required to identify the effects of face-to-face counselling on longterm outcomes such as cardiovascular disease mortality. (IRB number: 1909-006-16282).

\section{Background}

In Korea, health check-ups can be funded by three sources: the National Health Insurance Corporation, workplaces/workplace health insurance, and private citizens. According to the 2013 National Health Statistics [1], 82\% of check-ups were funded by the National Health Insurance Corporation, $10.5 \%$ were funded privately, and $12.0 \%$ were funded by other sources, such as workplaces or workplace insurance. In previous studies [2-4], private health screening rates were approximately $11-14 \%$. Recently, private 
check-ups have been increasing in popularity because they provide not only a greater variety of examinations, but also more satisfactory services to examinees $[3,5]$.

In 2019, the Korea Centers for Disease Control and Prevention reported that recent policies and projects, aimed at preventing and managing chronic diseases, succeeded in decreasing the standardised mortality and avoidable mortality rates of a number of major chronic diseases [6]. Despite this progress, mortality rates due to chronic diseases continue to rise. In fact, chronic diseases account for $79.8 \%$ of all deaths. Medical expenses for non-communicable diseases amount to 57.1 trillion won (83.9\% of total medical expenses) and remain a significant burden on national finance.

Previous studies $[7,8]$ have shown that frequent medical visits at the beginning of the treatment of chronic disease increase the long-term compliance of patients. For this reason, it is important to connect patients with appropriate medical services after initial medical examinations. To this end, the National Health Insurance Corporation began to provide lifestyle counselling for individuals undergoing transitional age health check-ups, in conjunction with the continued implementation of follow-up projects in connection with community health centres. Although private medical examinations cost more, no regulations exist relating to aftercare, following these examinations. Further, national monitoring does not occur for aftercare in these cases. It is also not known whether post-check-up counselling and education can help improve chronic disease management in large populations, given rising numbers of private health check-ups. Therefore, we aimed to identify the best counselling method to provide after private check-ups, to improve chronic disease management.

\section{Methods}

This study included individuals who received private health check-ups at the Chung-Ang University Hospital Health Check-up Center. Participants were 13,819 adults over the age of 20 who received at least three health check-ups from September 2013 to August 2019. We retrospectively reviewed 59,279 reports from medical examinations.

The results of health examinations were delivered via three counselling mediums: mail, telephone, or face-to-face. In mail counselling, a letter containing the check-up results, and the relevant counselling is sent to the patient's home. In telephone counselling, the doctor speaks directly with the examinee and provides check-up results along with advice on health and disease management, in addition to the mailed results. In face-to-face counselling, the examinee visits the centre and consults with the doctor regarding the results. Among these counselling methods, only patients who received the same counselling method three or more times consecutively were included. In general, health examinations are performed every two years, so the last six years have been set as the study period.

6,700 participants who did not receive the same counselling method more than three times consecutively were excluded and 80 participants were excluded due to missing data of the results of the check-ups. The final number of participants included in the study was 7,039 (Fig. 1). This study was approved by the Institutional Review Board of Chung-Ang University Hospital (IRB number: 1909-006-16282). 
For each participant, we obtained information on demographic characteristics (sex, age), health examination results (height, weight, body mass index, waist circumference, systolic blood pressure, diastolic blood pressure, creatinine, aspartate transaminase (AST), alanine transaminase (ALT), gamma-

glutamyl transferase ( $\mathrm{\gamma}-\mathrm{GT})$, total cholesterol, triglycerides, HDL cholesterol, fasting blood glucose, glycosylated haemoglobin), total number of check-ups, forms of counselling, and results of counselling. Body mass index (BMI) was obtained by rounding the weight $(\mathrm{kg})$ divided by the square of the height $(\mathrm{m})$ to the second decimal place. LDL cholesterol was calculated using the Friedewald equation when the concentration of triglycerides was less than $400 \mathrm{mg} / \mathrm{dL}$. All analyses were conducted using IBM SPSS 23. Values of $\mathrm{P}<0.05$ were considered statistically significant.

First, the baseline characteristics of the participants were compared according to the three counselling methods. For categorical variables, we performed chi-square tests and presented variable frequencies and percentages. For continuous variables, we performed one-way analyses of variance (ANOVAs), performed Scheffé post-hoc analyses, and presented means and standard deviations.

Second, changes in the results of medical examination related to chronic diseases were defined as the difference between the last and the first examination value. We performed analyses of covariance (ANCOVA) after adjusting for age, sex, and number of examinations as variables to determine correlations between counselling methods and the changes in examination values. These adjustments were carried out by presenting estimated marginal means which were adjusted for covariates, which was a common method of identifying differences between groups. If an ANCOVA produced significant differences, pairwise comparisons with Bonferroni correction were conducted between groups.

\section{Results}

Table 1 shows the baseline characteristics of the study population. 6,036 people (86\%) chose mail counselling for medical examination results, 386 people (5\%) chose telephone counselling with doctors, and 617 people (9\%) chose face-to-face counselling at examination centres with doctors. The mean age of all participants was 48.20 years and the mean number of health check-ups was 4.23 over 6 years. Participants' consecutive consultations of the same type and the associated numbers of participants are as follows: three consultations, 3,161 participants (45\%); four consultations, 1,479 participants (21\%); five consultations, 1,344 participants (19\%); six consultations, 1,055 participants (15\%). 
Table 1

Baseline characteristics of the study population according to method of counselling for check-up results.

\begin{tabular}{|c|c|c|c|c|c|}
\hline & $\begin{array}{l}\text { Total } \\
(\mathrm{N}=7,039)\end{array}$ & $\begin{array}{l}\text { Mail } \\
\text { counselling } \\
(n=6,036)\end{array}$ & $\begin{array}{l}\text { Telephone } \\
\text { counselling } \\
(n=386)\end{array}$ & $\begin{array}{l}\text { Face to face } \\
\text { counselling } \\
(n=617)\end{array}$ & $\begin{array}{l}\text { P- } \\
\text { value }^{a}\end{array}$ \\
\hline Sex: Men & $4037(57.4)^{b}$ & $3476(57.6)$ & 191(49.5) & $370(60.0)$ & $<0.01$ \\
\hline Age (years) & $\begin{array}{l}48.20 \pm \\
8.99^{c}\end{array}$ & $\begin{array}{l}46.46 \pm \\
7.80\end{array}$ & $55.41 \pm 6.65$ & $60.77 \pm 8.91$ & $<0.001$ \\
\hline $\begin{array}{l}\text { Total number of health } \\
\text { checks }\end{array}$ & $4.23 \pm 1.18$ & $4.22 \pm 1.17$ & $4.44 \pm 1.15$ & $4.18 \pm 1.21$ & $<0.01$ \\
\hline BMI $\left(\mathrm{kg} / \mathrm{m}^{2}\right)^{\mathrm{d}}$ & $\begin{array}{l}23.63 \pm \\
3.29\end{array}$ & $\begin{array}{l}23.60 \pm \\
3.31\end{array}$ & $23.32 \pm 3.03$ & $24.13 \pm 3.19$ & $<.001$ \\
\hline $\begin{array}{l}\text { Waist circumference } \\
(\mathrm{cm})\end{array}$ & $\begin{array}{l}82.78 \pm \\
9.05\end{array}$ & $\begin{array}{l}82.68 \pm \\
9.07\end{array}$ & $81.62 \pm 8.97$ & $84.45 \pm 8.68$ & $<0.001$ \\
\hline $\begin{array}{l}\text { Systolic blood pressure } \\
(\mathrm{mmHg})\end{array}$ & $\begin{array}{l}118.73 \pm \\
15.29\end{array}$ & $\begin{array}{l}118.45 \pm \\
15.32\end{array}$ & $118.65 \pm 14.91$ & $121.48 \pm 15.03$ & $<.001$ \\
\hline $\begin{array}{l}\text { Diastolic blood } \\
\text { pressure (mmHg) }\end{array}$ & $\begin{array}{l}71.93 \pm \\
13.09\end{array}$ & $\begin{array}{l}71.84 \pm \\
13.43\end{array}$ & $71.86 \pm 10.66$ & $72.88 \pm 10.83$ & 0.17 \\
\hline Creatinine $(\mathrm{mg} / \mathrm{dL})$ & $0.79 \pm 0.18$ & $0.79 \pm 0.17$ & $0.76 \pm 0.17$ & $0.80 \pm 0.19$ & $<0.01$ \\
\hline AST (IU/L) & $\begin{array}{l}25.45 \pm \\
14.72\end{array}$ & $\begin{array}{l}25.10 \pm \\
15.02\end{array}$ & $27.61 \pm 13.20$ & $27.46 \pm 12.17$ & $<.001$ \\
\hline ALT (IU/L) & $\begin{array}{l}24.82 \pm \\
19.34\end{array}$ & $\begin{array}{l}24.71 \pm \\
19.54\end{array}$ & $24.97 \pm 18.76$ & $25.83 \pm 17.60$ & 0.39 \\
\hline Y-GT (IU/L) & $\begin{array}{l}31.78 \pm \\
35.31\end{array}$ & $\begin{array}{l}31.50 \pm \\
34.25\end{array}$ & $33.02 \pm 45.06$ & $33.70 \pm 38.42$ & 0.26 \\
\hline $\begin{array}{l}\text { Total cholesterol } \\
(\mathrm{mg} / \mathrm{dL})\end{array}$ & $\begin{array}{l}196.40 \pm \\
35.60\end{array}$ & $\begin{array}{l}196.09 \pm \\
35.40\end{array}$ & $197.91 \pm 34.81$ & $198.48 \pm 37.87$ & 0.20 \\
\hline Triglyceride (mg/dL) & $\begin{array}{l}116.87 \pm \\
84.84\end{array}$ & $\begin{array}{l}116.90 \pm \\
86.19\end{array}$ & $110.85 \pm 76.60$ & $120.35 \pm 75.88$ & 0.23 \\
\hline $\begin{array}{l}\text { HDL cholesterol } \\
(\mathrm{mg} / \mathrm{dL})\end{array}$ & $\begin{array}{l}54.36 \pm \\
11.69\end{array}$ & $\begin{array}{l}54.27 \pm \\
11.62\end{array}$ & $56.24 \pm 12.80$ & $54.13 \pm 11.64$ & 0.01 \\
\hline $\begin{array}{l}\text { LDL cholesterol } \\
(\mathrm{mg} / \mathrm{dL})^{\mathrm{e}}\end{array}$ & $\begin{array}{l}118.66 \pm \\
32.21\end{array}$ & $\begin{array}{l}118.44 \pm \\
31.77\end{array}$ & $119.51 \pm 33.33$ & $120.29 \pm 35.64$ & 0.41 \\
\hline $\begin{array}{l}\text { Fasting blood glucose } \\
(\mathrm{mg} / \mathrm{dL})\end{array}$ & $\begin{array}{l}98.93 \pm \\
16.06\end{array}$ & $\begin{array}{l}98.18 \pm \\
15.27\end{array}$ & $100.22 \pm 17.09$ & $105.46 \pm 20.79$ & $<001$ \\
\hline $\begin{array}{l}\text { Glycosylated } \\
\text { hemoglobin (\%) }\end{array}$ & $5.35 \pm 0.55$ & $5.32 \pm 0.53$ & $5.45 \pm 0.56$ & $5.61 \pm 0.69$ & $<.001$ \\
\hline
\end{tabular}




$\begin{array}{lllll}\text { Total } & \text { Mail } & \begin{array}{l}\text { Telephone } \\ \text { counselling }\end{array} & \begin{array}{l}\text { Face to face } \\ \text { counselling }\end{array} & \begin{array}{l}\text { P- } \\ \text { value }^{a}\end{array} \\ (N=7,039) & \begin{array}{l}\text { counselling } \\ (n=6,036)\end{array} & (n=386) & (n=617) & \end{array}$

All values were taken from the subject's first examination.

BMI, Body mass index; AST, Aspartate transaminase; ALT, Alanine transaminase; $\gamma-G T$, gammaglutamyltransferase.

a: P-values are from chi-squared tests or one-way analyses of variance (ANOVA).

b: Number (\%) of categorical variables.

c: Mean \pm Standard deviation of continuous variables

d: Body mass index was calculated as body weight in kilograms divided by height in meters squared.

e: LDL cholesterol value was based on the Friedewald equation, if triglyceride is less than $400 \mathrm{mg} / \mathrm{dL}$.

There were statistically significant differences in counselling methods for most variables except diastolic blood pressure, alanine transaminase (ALT), gamma-glutamyltransferase ( $\mathrm{Y}-\mathrm{GT}$ ), total cholesterol, triglyceride, and LDL cholesterol. Post-hoc analysis showed that face-to-face counselling group values were higher than the mail and telephone counselling groups in terms of age $(P<0.001), B M I(P<0.001)$, waist circumference $(P<0.001)$, systolic blood pressure $(P<0.05)$, creatinine levels $(P<0.01)$, aspartate transaminase (AST) $(P<0.001)$, fasting blood sugar levels $(P<0.001)$, and glycosylated haemoglobin (Hba1c) levels $(P<0.001)$; but was lower in terms of HDL cholesterol $(P<0.05)$.

Table 2 and Fig. 2 show the changes in the results of medical examination related to chronic diseases according to counselling method after adjusting for age, sex, and the total number of examinations. There were no statistically significant differences in obesity indices (BMI, waist circumference), blood pressure (systolic blood pressure, diastolic blood pressure), liver function parameters (AST, ALT, Y-GT), renal function parameters (creatinine), or glucose metabolic indices (glycosylated haemoglobin). Although there was a statistically significant difference in fasting blood glucose $(P=0.02)$, the pairwise comparison showed that fasting blood glucose levels differed only between mail and telephone counselling groups, not among all groups. 
Table 2

Changes in the results related to chronic diseases, except lipid profile, according to counselling method after check-ups.

\begin{tabular}{|c|c|c|c|c|}
\hline & $\begin{array}{l}\text { Mail } \\
\text { counselling } \\
(n=6,036)\end{array}$ & $\begin{array}{l}\text { Telephone } \\
\text { counselling } \\
(n=386)\end{array}$ & $\begin{array}{l}\text { Face to face } \\
\text { counselling } \\
(n=617)\end{array}$ & $\begin{array}{l}\text { P- } \\
\text { value }^{a}\end{array}$ \\
\hline $\mathrm{BMI}\left(\mathrm{kg} / \mathrm{m}^{2}\right)^{\mathrm{b}}$ & $0.09 \pm 0.02$ & $-0.02 \pm 0.06$ & $0.05 \pm 0.05$ & 0.22 \\
\hline Waist circumference $(\mathrm{cm})$ & $1.07 \pm 0.06$ & $0.81 \pm 0.23$ & $0.89 \pm 0.20$ & 0.48 \\
\hline $\begin{array}{l}\text { Systolic blood pressure } \\
(\mathrm{mmHg})\end{array}$ & $-1.87 \pm 0.17$ & $-2.16 \pm 0.66$ & $-3.09 \pm 0.57$ & 0.13 \\
\hline $\begin{array}{l}\text { Diastolic blood pressure } \\
(\mathrm{mmHg})\end{array}$ & $0.17 \pm 0.17$ & $0.37 \pm 0.66$ & $-1.15 \pm 0.56$ & 0.07 \\
\hline Creatinine (mg/dL) & $0.00 \pm 0.00$ & $0.01 \pm 0.00$ & $0.01 \pm 0.00$ & 0.14 \\
\hline AST (IU/L) & $0.46 \pm 0.20$ & $-0.12 \pm 0.80$ & $-0.41 \pm 0.69$ & 0.44 \\
\hline ALT (IU/L) & $0.83 \pm 0.25$ & $0.21 \pm 0.99$ & $-0.15 \pm 0.85$ & 0.51 \\
\hline Y-GT (IU/L) & $0.11 \pm 0.34$ & $2.08 \pm 1.35$ & $-1.24 \pm 1.16$ & 0.15 \\
\hline $\begin{array}{l}\text { Fasting blood glucose } \\
(\mathrm{mg} / \mathrm{dL})\end{array}$ & $-0.55 \pm 0.16$ & $1.31 \pm 0.65$ & $-0.25 \pm 0.56$ & 0.02 \\
\hline Glycosylated hemoglobin (\%) & $0.15 \pm 0.00$ & $0.16 \pm 0.02$ & $0.16 \pm 0.02$ & 0.97 \\
\hline \multicolumn{5}{|c|}{$\begin{array}{l}\text { The changes in values were determined by the difference between the last examination value and the } \\
\text { first examination value of each subjects. All values are mean } \pm \text { standard error. }\end{array}$} \\
\hline \multicolumn{5}{|c|}{$\begin{array}{l}\text { BMI, Body mass index; AST, Aspartate transaminase; ALT, Alanine transaminase; } \gamma \text {-GT, gamma- } \\
\text { glutamyltransferase. }\end{array}$} \\
\hline \multicolumn{5}{|c|}{ a: P-values are from analyses of covariance (ANCOVA). } \\
\hline $\begin{array}{l}\text { b: Body mass index (BMI) was } \\
\text { squared }(\mathrm{kg} / \mathrm{m} 2)\end{array}$ & alculated as & dy weight in & divided by $\mathrm{h}$ & \\
\hline
\end{tabular}

On the other hand, even after pairwise comparison with Bonferroni correction, there were significant differences in total cholesterol $(P<0.001)$ and LDL cholesterol $(P<0.001)$ between the face-to-face counselling and the other two groups (Fig. 2). In other words, in the face-to-face counselling group, total cholesterol and LDL cholesterol showed significant improvement compared to the other two groups. In addition, there were no significant differences but similar tendencies in triglyceride levels $(P=0.06)$.

\section{Discussion}


Those who received examination results via face-to-face counselling were the oldest and had the poorest cardiometabolic parameters (BMI, waist circumference, systolic blood pressure, HDL cholesterol) and glucose metabolic indices (fasting blood glucose, glycosylated haemoglobin) as compared to the groups that received mail or telephone counselling. However, in the face-to-face counselling group, total cholesterol and LDL cholesterol levels showed greater improvement after health examination, compared to the other two groups. This pattern of results was similar but non-significant for triglyceride levels.

Previous studies $[4,5]$ have shown that private check-up examinees have lower subjective and objective health statuses. Shin et al. [5] compared those who received both the National Health Insurance Service health check-ups and the private health check-ups with those who received only the private health checkups. They reported that those who received both private and national check-ups were aware of their poor health status and had higher obesity levels. In addition, those who answered 'normal', 'healthy' or 'very healthy' for subjective health status were $66-71 \%$ less likely to receive private check-ups than those who answered 'bad'. However, this study had limitations in that it had only 297 participants. Kang et al. [4], from the nationwide Korean Longitudinal Study of Ageing (KLoSA), demonstrated that patients who had private check-ups had lower subjective health statuses. The incidence of hypertension and cancer was also higher for these patients than for patients who did not receive private check-ups. Furthermore, Yeo [3] reported that the more chronic disease, the higher the probability of receiving private check-ups.

In this study, participants may have chosen face-to-face counselling instead of mail or telephone counselling because they required detailed explanation of their conditions. Their older age, less favourable check-ups results, and self-awareness regarding their health statuses may have led to them choosing face-to-face counselling. However, during the six years of study period, proportions of counselling methods remained unchanged: $79.1 \%$, mail counselling; $10.5 \%$, telephone counselling; and $10.5 \%$, face-to-face counselling. This indicates that examinees seem to choose the same counselling method as before without concerned about the form of counselling they receive after an examination.

In patients with dyslipidaemia, lifestyle modifications such as proper diet, regular aerobic exercise, and weight control can reduce total cholesterol, LDL cholesterol, and triglyceride by $7-18 \%$, and increase HDL cholesterol by $2-18 \%$ [9]. However, lapses into bad habits may have to be overcome repeatedly, before positive lifestyle modifications become cemented [10]. During this transitional phase, maintenance motives, self-regulation, resources, habits, and contextual influences are required for the instatement of lifestyle changes. Also, in a systematic review and meta-analysis of the motivational interview on behavioural change, Sune et al. [11] reported that the interview was effective only if conducted more than once and was always effective if conducted more than five times. In subsequent systematic reviews, Patnode et al. [12] demonstrated that changes to the number of counselling sessions effected proportional behavioural change. During the design of the current study, this shaped the decision to recruit only patients who received three or more sessions.

Despite relatively high overall satisfaction rates with private health examinations, little counselling and education seems to take place after these examinations. A previous study [5] on the satisfaction survey 
of the examinees showed that both national and private check-ups received the lowest score in 'sufficiency of counselling and education after check-ups', and the next lowest score in 'relevant data after check-ups/excellent guidance for follow-up'. Moreover, the demand for counselling is increasing.

In a previous study [11], short motivational interviewing of only 15 minutes was shown to be effective in the treatment of lifestyle problems and disease. Therefore, patients who review the results of their examinations with their doctors and talk about a health promotion plan could develop improved lipid profiles relative to those who simply read letters containing their results and consultation information. Although a few reports $[13,14]$ have indicated that telemedicine is more cost-effective than face-to-face medical care, due to recent advances in information and communication technology (ICT), the results of the current study support the most basic principle [15]-direct patient education is the most effective method of managing chronic diseases.

There are several limitations to our study. First, ours was a single-centre study and may not have contained a sample that was representative of the overall population. Second, since the participants' previous histories were not included, those with normal lipid profiles and no treatment or counselling needed may have also been included in the study. In addition, this study did not consider that the goals and treatment methods associated with dyslipidaemia differ according to levels of cardiovascular risks. However, in a recent study [16] of young adults aged 20 to 39 years in Korea, the risks of ischaemic heart disease and cerebrovascular disease were reduced if total cholesterol levels were reduced to a lower class than was observed in the previous examination, when dividing total cholesterol levels into the following categories: low ( $<180 \mathrm{mg} / \mathrm{dL})$, middle $(180-240 \mathrm{mg} / \mathrm{dL})$, high ( $\geq 240 \mathrm{mg} / \mathrm{dL})$. Therefore, it is meaningful to compare the degree of change in cholesterol levels alone, as was done in the current study. Third, because we did not include the drug history of the participants, changes in cholesterol levels may be attributable to drugs or other causes rather than the effects of lifestyle modifications. However, patients with dyslipidaemia have lower compliance rates with the drugs than do those with hypertension and diabetes [17-19]. And in previous studies [7], patients who received follow-up treatment within the first three months following medication had higher subsequent compliance rates, as compared to those who received no follow-up treatment. Therefore, regardless of drug effects, it is meaningful that compliance rates and the results of medical examination related to chronic diseases are improved due to increase in post-check-up behaviours, such as visiting the hospital and picking up medicine. Fourth, because the study included data from September 2013 to August 2019, it is impossible to know which forms of counselling were received before September 2013, and effects of these sessions cannot be overlooked. In order to correct for this problem, additional analyses of chi-square tests, one-way analyses of variance(ANOVA) and Scheffé post-hoc analyses were performed only for participants $(n=4,919)$ who conducted the first check-ups at our health check-up centre. However, the baseline characteristics of the participants were not significantly different from those of the participants in this study. In addition, even if the first examination was conducted at our health check-up centre, it may not be the first examination in one's life, so the influence of a previous examination cannot be completely excluded, using any analysis method. 


\section{Conclusion}

The face-to-face counselling with doctors seems to be more effective at improving lipid profiles than nonface-to-face or printed counselling. Further research is required to identify the effects of face-to-face counselling on long-term health outcomes, such as cardiovascular disease mortality.

\section{Abbreviations}

BMI: Body mass index; HDL-C:High-density lipoprotein cholesterol; LDL-C:Low-density lipoprotein cholesterol; TC:Total cholesterol; TG:Triglyceride; AST:aspartate transaminase; ALT:alanine transaminase; $\mathrm{Y}$-GT:gamma-glutamyl transferase; ANCOVA:Analyses of covariance

\section{Declarations}

\section{Availability of data and materials}

The datasets used and analyzed during the current study are available from the corresponding author on reasonable request.

\section{Ethics approval and consent to participate}

The study protocol was reviewed and approved by the Institutional Review Board of our Medical Center (IRB No. 1909-006-16282). Since there is no personally identifiable information and therapeutic intervention, the risk of the subjects was low. So, we were exempt from the consent.

Trial registration: Institutional Review Board of Chung-Ang University Hospital, 1909-006-16282. Registered 17 December 2019 - Retrospectively registered, https://eirb.cauhs.or.kr/

\section{Consent for publication}

Not applicable

\section{Competing interests}

The authors declare that they have no competing interests

\section{Funding}

This study did not receive any specific grant from any funding agency in the public, commercial or notfor-profit sectors. 


\section{Authors' contributions}

Conception and design: NYK, JHK and SHC, Patient enrollment: SAK, Data acquisition: JHK, Data analysis, interpretation and manuscript: NYK and JHK, Approval of final manuscript: all authors.

\section{Acknowledgements}

Not applicable

\section{References}

1. Korea Centers for Disease Control and Prevention. Korea National Health Statistics 2013. Korea National Health and Nutrition Examination Survey (KNHANES VI-1). https://knhanes.cdc.go.kr/knhanes/sub04/sub04_03.do?classType=7. Accessed 12 Feb 2020.

2. Kim HS. A study on the efficient policy of health examination based on comparing private health sector with public health sector [dissertation]. Dongdaemun-gu (Seoul): Univ of Kyunghee, 2010.

3. Yeo JY, Jeong HS. Determinants of health screening and its effects on health behaviors. Korean J Health Policy Adm. 2012;22(1):49-64.

4. Kang SW, You CH, Kwon YD. The determinants of the use of opportunistic screening programs in Korea. J Prev Med Public Health. 2009;42(3):177-82.

5. Shin YS, Park CY, Jung SH, Jung HY, Kang HY. Comparison of customer satisfaction with health examination programs provided by the Korea National Health Insurance and private healthcare organizations in Korea. J Korean Soc Qual Assur Health Care. 2006;12(1):40-51.

6. Korea Centers for Disease Control and Prevention. The fact book of chronic disease 2019: the current status and issues of chronic disease. Available at: http://www.cdc.go.kr/gallery.es? mid=a20503020000\&bid=0003. Accessed 12 Feb 2020.

7. Benner JS, Tierce JC, Ballantyne CM, et al. Follow-up lipid tests and physician visits are associated with improved adherence to statin therapy. Pharmacoeconomics. 2004;22(Suppl 3):13-23.

8. Campione JR, Sleath B, Biddle AK, Weinberger M. The influence of physicians' guideline compliance on patients' statin adherence: a retrospective cohort study. Am J Geriatr Pharmacother. 2005;3(4):229-39.

9. Bronas UG, Salisbury D. Clinical strategies for managing dyslipidemias. Am J Lifestyle Med. 2014;8:216-30.

10. Kwasnicka D, Dombrowski SU, White M, Sniehotta F. Theoretical explanations for maintenance of behaviour change: a systematic review of behaviour theories. Health Psychol Rev. 2016;10(3):27796.

11. Rubak S, Sandbaek A, Lauritzen T, Christensen B. Motivational interviewing: a systematic review and meta-analysis. Br J Gen Pract. 2005;55(513):305-12. 
12. Patnode CD, Evans CV, Senger CA, Redmond N, Lin JS. Behavioral counselling to promote a healthful diet and physical activity for cardiovascular disease prevention in adults without known cardiovascular disease risk factors: updated evidence report and systematic review for the us preventive services task force. JAMA. 2017;318(2):175-93.

13. Hjelm NM. Benefits and drawbacks of telemedicine. J Telemed Telecare. 2005;11(2):60-70.

14. Delaigue S, Bonnardot L, Steichen $\mathrm{O}$, et al. Seven years of telemedicine in Médecins Sans Frontières demonstrate that offering direct specialist expertise in the frontline brings clinical and educational value. J Glob Health. 2018 Dec;8(2):020414.

15. Rakel R, Rakel D. Textbook of family medicine. 9th ed. Philadelphia: Elsevier; 2016.

16. Jeong SM, Choi S, Kim K, et al. Effect of change in total cholesterol levels on cardiovascular disease among young adults. J Am Heart Assoc. 2018;7(12).

17. Larsen J, Vaccheri A, Andersen M, Montanaro N, Bergman U. Lack of adherence to lipid-lowering drug treatment. A comparison of utilization patterns in defined populations in Funen, Denmark and Bologna, Italy. Br J Clin Pharmacol. 2000;49(5):463-71.

18. Chapman RH, Benner JS, Petrilla AA, et al. Predictors of adherence with antihypertensive and lipidlowering therapy. Arch Intern Med. 2005;165(10):1147-52.

19. Parris ES, Lawrence DB, Mohn LA, Long LB. Adherence to statin therapy and LDL cholesterol goal attainment by patients with diabetes and dyslipidemia. Diabetes Care. 2005;28(3):595-9.

\section{Figures}




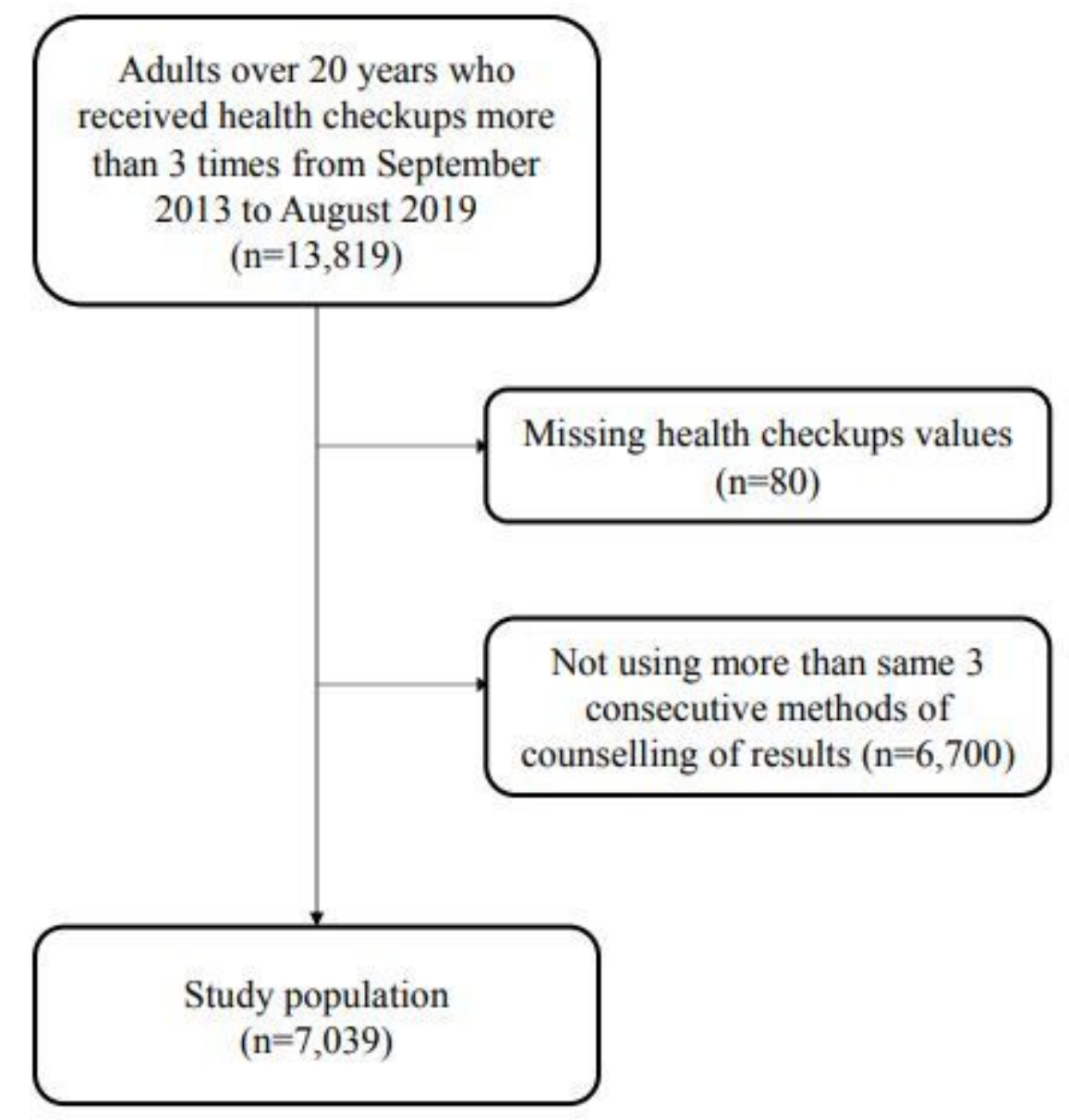

Figure 1

Flow chart of inclusion and exclusion for the study population 
$\mathrm{mg} / \mathrm{dL} 8$

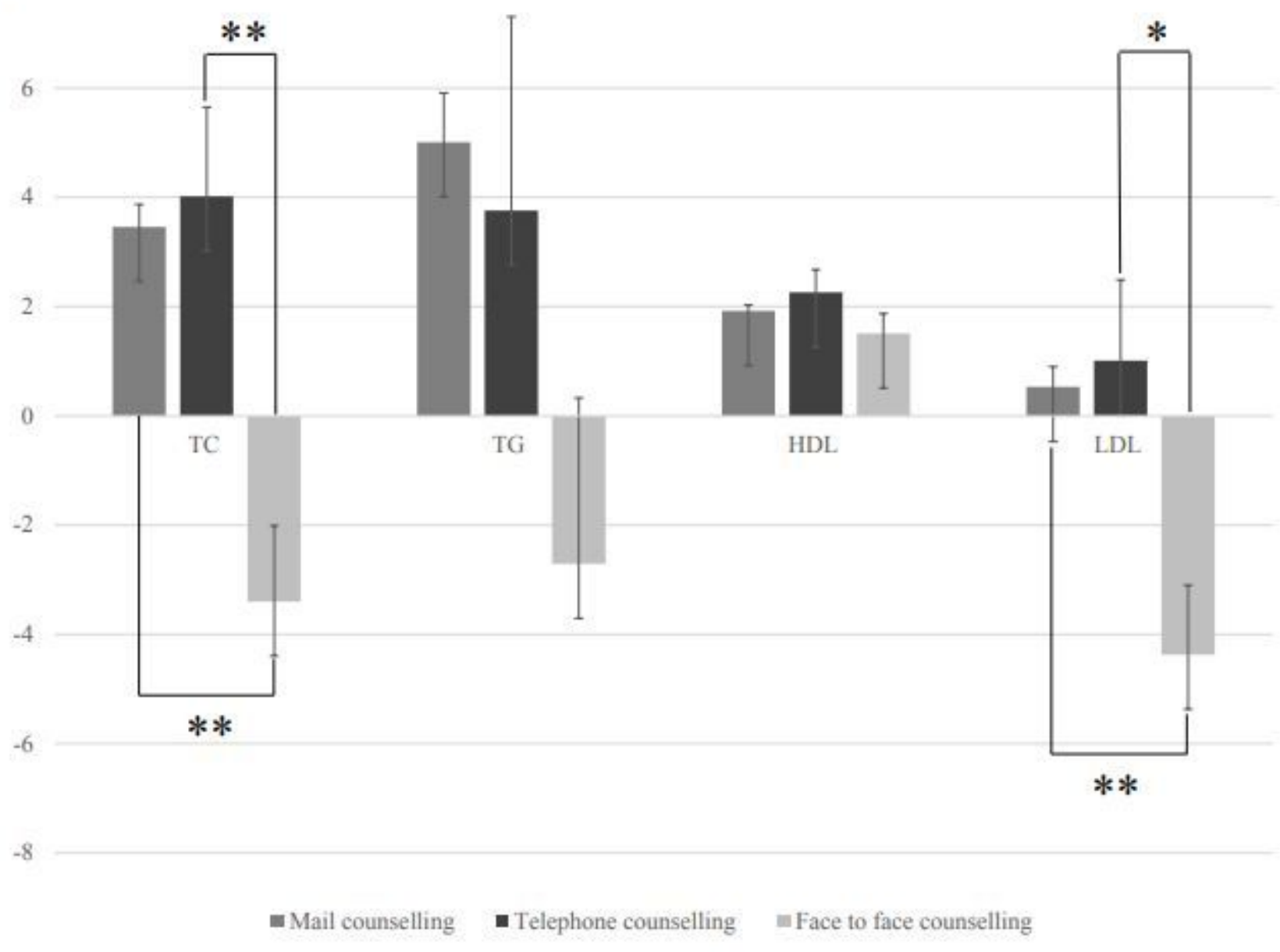

Figure 2

Changes in lipid profile according to counselling method. Note: All values are mean \pm Standard error. TC, total cholesterol; TG, triglyceride *P<0.05, ** $P<0.001$ 